\title{
A comunidade dos contemporâneos
}

\author{
Eduardo Yuji Yamamoto
}

Resumo: A partir da ideia de "contemporâneo", presente em Giorgio Agamben, propõe-se aqui dois caminhos para se conceber a comunidade hoje: 1) A partir do pensamento sociológico que entende a comunidade como substância comum compartilhada (território, cultura, etnia, classe, etc.) ou; 2) A partir do que denominamos filósofos contemporâneos da comunidade (Maurice Blanchot, Jean-Luc Nancy, Georges Bataille, Roberto Espósito e Giorgio Agamben) que dessubstancializam a comunidade, compreendendo-a como experiência da dessubjetivação (vinculação). O presente texto apresenta, de maneira breve, a articulação entre esses filósofos num eixo comum (diferença ontológica) e sua possível inscrição como problema comunicacional.

Palavras-chave: vinculação; communitas; hermenêutica; diferença ontológica

Abstract: The community of contemporaries - Starting from the notion of "contemporary" expressed by Giorgio Agamben, we propose two ways of thinking about community today: 1) From the sociological standpoint, which sees community as a shared common substance (territory, culture, ethnicity, class, etc.), and 2) Based on the so-called contemporary philosophers of community (Maurice Blanchot, Jean-Luc Nancy, Georges Bataille, Roberto Esposito and Giorgio Agamben), who desubstantiate the community, understanding it as the experience of desubjectification (binding). This paper briefly discusses the relationship between these philosophers on a common issue (ontological difference) and its possible application as a communication problem.

Keywords: binding; communitas; hermeneutics; ontological difference

\section{Introdução}

A questão sobre a contemporaneidade proposta por Giorgio Agamben é seminal para pensarmos hoje na urgência de uma reinterpretação do conceito de comunidade. Agamben define o contemporâneo como elemento desconexo, excêntrico, em desacordo com o seu tempo, problematizando o seu uso convencional, isto é, como sinônimo de 
momento presente. "O contemporâneo é o intempestivo", já assinalava Nietzsche em suas "Considerações intempestivas". Agamben, por sua vez, o complementa:

Pertence verdadeiramente ao seu tempo, é verdadeiramente contemporâneo, aquele que não coincide perfeitamente com este [...] Aqueles que coincidem muito plenamente com a época, que em todos os aspectos a esta aderem perfeitamente, não são contemporâneos porque, exatamente por isso, não conseguem vê-la, não podem manter fixo o olhar sobre ela (AGAMBEN, 2009, p. 58-59).

O contemporâneo, nesse caso, nada tem a ver com periodização histórica. Trata-se de uma relação disjuntiva com o tempo, independente de este ser presente, passado ou futuro. Essa relação é, obrigatoriamente, de quebra, nunca de continuidade: há um fluxo que nos atravessa, carregando-nos junto dele; no meio do caminho há uma falha, um acontecimento, que impede a nossa tranquila jornada. No entanto, acrescenta Agamben, isso ainda não é o contemporâneo. Pode-se dar conta dessa falha e ignorá-la, continuar serenamente o percurso. Contemporâneo é a aventura do pensamento no interior da fratura, o olhar insistente sobre este fundo abissal que nos impele a uma frustrada investigação, qual seja, atingir o fundo do abismo, ainda que já se esteja consciente de sua infinitude.

Esse abismo não é estranho a muitos pensadores como Georges Bataille, Maurice Blanchot, Jean-Luc Nancy e Roberto Espósito. O desajuste temporal que liga esses pensadores numa mesma contemporaneidade provém da visualização de um colapso do comum, a falência da moderna concepção de comunidade que, no século XX, autorizou práticas autoritárias e excluiu as manifestações singulares do coletivo. De fato, a percepção desses pensadores tem sido notória em suas críticas à noção "substancialista" de comunidade, base de um essencialismo inquisidor que legitimou a construção de barreiras físicas e imaginárias, obstruindo os processos vinculativos, constituidores do homem.

Dentre esses contemporâneos, no entanto, cabe destacar a figura de Espósito. A ele devemos uma distinção fundamental, a organização da totalidade dos estudos sobre o conceito de comunidade em duas perspectivas: a substancialista e a dessubstancialista. Essa distinção é a novidade introduzida pelo autor nos estudos conceituais de comunidade definida, segundo ele, em sentido estrito, quer dizer, como fenômeno vinculativo humano e não absolutamente como formação histórico-social particular ${ }^{1}$.

De acordo com a organização proposta, a perspectiva substancialista da comunidade abarcaria toda a "filosofia política" tradicional, onde se arrolam correntes teóricas e conceitos como a Gemeinschaft, o neocomunitarismo norte-americano e a ética da comunicação. Tal perspectiva, afirma Espósito (2007, p. 156), "parte sempre dos indivíduos pré-constituídos - conservando-os como tais, ou fundindo-os num indivíduo maior".

1 Com isso evita-se a referência do termo exclusivamente às formações sociais heterogêneas que precederam a sociedade urbano-industrial (comum no quadro geral das Ciências Sociais), ou seja, como designativo da vida clânica, rural, idílica (inspirada pela literatura romântica alemã); ou ainda como sinônimo de tribo, corporação (guilda), vila ou pequena cidade medieval. 
Em outra perspectiva (dessubstancialista), pelo contrário, que "parte sempre da relação do compartilhamento" de uma dívida originária (diferença ontológica), Espósito vê despontar o "grande pensamento da comunidade", onde comparece a noção de communitas. Vale a pena resgatar este extraordinário conceito.

Communitas é a palavra latina para designar comunidade. É a partir dela que Espósito extrai dois importantes radicais, cum e munus. Ao passo que cum revela a presença incontornável de um outro (um além de mim), no segundo radical (munus), Espósito encontra três significados possíveis: onus, officium e donum. Chama-lhe atenção o fato de donum (dom) pertencer a um mesmo conjunto semântico que indica dever, dívida, obrigação. Afinal, como um dom haveria de ser obrigatório? Não deveria, pelo contrário, ser algo espontâneo? Ests pergunta norteará toda reflexão de Espósito sobre o conceito de comunidade que, ao final, concluirá: se donum (munus) institui uma doação obrigatória, e cum refere-se à presença insistente de um outro (que está oculto), cum+munus (ou communitas) significa um tipo de relação em que o sujeito se doa incondicionalmente ao outro (qualquer, indefinido), logo, à comunidade enquanto outro na condição de virtual.

Esse é, segundo Espósito, o significado arcaico da comunidade obliterado pelo pensamento moderno (subjetivista), a externalidade que corrói o sujeito.

[...] o munus que a communitas compartilha não é uma propriedade ou pertença. Não é uma possessão, mas ao contrário, uma dívida, uma prenda, um dom a dar. Eé, portanto, o que vai determinar, o que está por converter-se, o que virtualmente já é, uma falta. Um 'dever' une os sujeitos da comunidade - no sentido de que 'te devo algo', e não no sentido de que 'me deves algo' - que faz com que não sejam inteiramente donos de si mesmos. Em termos mais precisos, os expropria, em parte ou inteiramente, sua propriedade inicial, sua propriedade mais própria, ou seja, sua subjetividade (ESPÓSITO, 2007, p. 30-31, tradução nossa).

Tal interpretação, como se percebe, contraria a lógica comunitária vigente (aquisitiva, reparativa), que concebe a comunidade muito mais como uma posse, uma propriedade, do que uma obrigação, uma "impropriedade" credores do que de devedores; muito mais uma instância de reafirmação dos sujeitos do que de dessubjetivação coletiva.

Essa mesma linha de pensamento é seguida por Nancy, outro contemporâneo, para quem comunidade é, antes de tudo, o "ser-em-comum", Mit-sein (ser-com):

O ser-em-comum se define e constitui por uma carga e, em última análise, não está a cargo de outra coisa senão do mesmo cum. Estamos a cargo de nosso com, ou seja, de nós. [...] Cum é algo que nos expõe: nos põe uns de frente aos outros, nos entrega uns aos outros, nos arrisca uns contra os outros e juntos nos entrega à experiência que não é outra coisa senão a de ser com (NANCY in ESPÓSITO, 2003, p. 16).

2 O fato mais importante da communitas, segundo Espósito, é o de ela revelar a "impropriedade" como traço comum e originário de todo ente, isto é, a condição devedora de todos os sujeitos, a predominância de um outro virtual (Mitsein) sobre estes: "Não é o próprio, mas o impróprio - ou mais drasticamente o outro - o que caracteriza o comum" (ESPÓSITO, 2007, p. 31). 
Como observadores posicionados numa extemporaneidade, Nancy e Espósito conseguem visualizar o ponto em que a estrutura da comunidade (tradicional) se rompe. Esse ponto é justamente o comum da comunidade, um comum antes apresentado como substância (território, língua, cultura, etc.), mas que a escavação genealógica revela um laço (cum), uma dívida (munus), que consome o sujeito até a revelação de seu fundo originário (nada, vazio, abismo indiferenciado) ${ }^{3}$.

\section{O comum como vazio originário: ou comunidade como diferença ontológica}

A referência a Heidegger aqui é inevitável e tanto mais proveitosa se considerarmos o escopo pleno de sua ontologia. Não por acaso que Espósito e Nancy, em seus questionamentos sobre o sentido derradeiro da comunidade (referida, respectivamente, como communitas e "ser-em-comum"), façam constantes menções a Ser e tempo e ao fracasso de Dasein para superar-se a si mesmo como consciência ou unidade existencial - pois lhe falta, ainda aí, uma diferença ontológica, um impróprio constituinte. Mas é tanto mais sugestivo o fato de Espósito utilizar a palavra substância (das leituras de Heidegger sobre Aristóteles) para qualificar a organização dos estudos conceituais da comunidade, encontrando na gênese ontológica da substância o ponto de inflexão de sua ontologia comunitária.

Substância, do latim substantia, é antes a tradução do grego ousia (ovøı́) que nos textos de Aristóteles aparece como aquilo que é sempre (presença constante), que perdura ou preexiste, enfim, que se situa para além de suas variações. Segundo as investigações heideggerianas, diferentemente da substantia, que, para os romanos, refere-se apenas ao que subjaz aos acidentes, a ousia impunha aos gregos uma determinação entre ser e tempo que permaneceu velada durante toda vigência da metafísica ocidental. Dois significados de ousia reforçam a ideia de uma presença constante: 1) um tempo específico, supratemporal, que dura além do instante daquilo que ocorre - ousia é o particípio do verbo grego ser ( $\varepsilon \imath v \iota$ ), utilizado na função não limitativa do tempo (a-orista), perdurando independentemente deste e; 2) a propriedade de raiz ou posse de uma terra, significado extraído das estruturas fáticas do mundo grego e utilizado para resolver problemas práticos do cotidiano.

Tais significados provêm do retorno de Heidegger à Grécia Antiga, de sua aventura hermenêutica para encontrar a estrutura de sentido fundamental que vigora até os nossos tempos (a compreensão do ser como ousia). Mas a ousia, enquanto aquilo que permanece no ente, que diz algo sobre ele (ser), guarda um sentido ainda mais originário, ${ }^{4}$ physis $(\phi v \sigma \iota \zeta)$, natureza e ente na totalidade.

\footnotetext{
As ideias de nada, vazio, abismo indiferenciado serão compreendidas por Deleuze (2007) como multiplicidade. 4 A relação entre ousia e physis não provém de sua morfologia linguística, mas da interpretação de Heidegger sobre o primeiro início da filosofia, a partir de uma lida com os pré-socráticos (em especial Heráclito). Esta aproximação se deve ao fato da physis designar emergência, abertura, brotar daquilo que vige e, nesta experiência, revelar algo como uma determinação ontológica do ente, experiência de essenciação do ser (ousia).
} 
Contudo, a interrogação desse significado da physis no próprio solo de sua proveniência revela uma dinâmica originária tanto mais contraditória: erigir-se emergente, mas também desdobrar-se que em si repousa.

Devemo-nos afastar completamente do conceito de "natureza". Pois physis significa o surgir emergente, que brota. O desabrochar e desprender-se que em si mesmo permanece. A partir de uma unidade originária se incluem e manifestam nesse vigor repouso e movimento. Nesse vigor (Walten) o presente se apresenta como ente. A vigência de tal vigor só se instaura a partir do ocultamento. Isso significa para os gregos: a aletheia (o des-ocultamento) se processa e acontece, quando o vigor se conquista a si mesmo como um mundo! Só através do mundo o ente faz ente. (HEIDEGGER, 1999, p. 89).

Para Heidegger, o revelar-se daquilo que é (ser) deve conservar essa dinâmica originária: arrancar o ser do não-ser que o constitui (desvelamento a partir do velado; o "ser" e o "vir-a-ser"5). Essa é a constância pressuposta na physis, mas que cede lugar, em Platão e Aristóteles, para a "ideia" e a "substância". Ou melhor, nesses dois filósofos, a constância da dinâmica originária (desvelamento e retração) é interpretada como constância de uma presença - daí a expressão de Derrida "metafísica da presença", inspirada na designação de Heidegger a essa primeira filosofia.

Essa breve incursão nos estudos de Heidegger sobre a gênese da substância aristotélica é importante para compreendermos a distinção ontológica operada por Espósito. Se a physis, que constitui a determinação ontológica originária, apresenta-se como dinâmica do desvelamento e retração, a comunidade, ao se pretender como princípio originário de

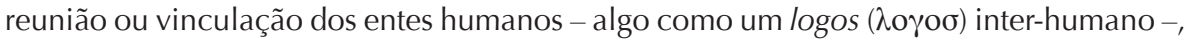
deveria considerar tal dinâmica enquanto determinante de sua própria ontologia. Em outras palavras: uma ontologia rigorosa da comunidade não poderia limitar-se apenas àquilo que ela reúne e mostra (substância), ignorando o que dela se separa, a região ontológica que a constitui, mas que se retrai ou se oculta naquilo que ganha presença (o não-ser ou vazio, segundo Heidegger; o impróprio e a des-substância, segundo Espósito). Daí a perspectiva dessubstancialista da comunidade, a restituição dessa região que devolve para sua ontologia o seu impróprio constituinte.

Tal delineamento pode ser observado na organização ontológica de Espósito: mostração da substância comum (a essência comunitária) e ocultamento daquilo que dela se separa (o cum ou munus obrigatório, a abertura incondicional ao solo originário). Se a perspectiva substancialista abrange os modos de ser da comunidade, fundados numa essência comum, portanto, reunindo sujeitos plenos ou indivíduos autossuficientes

5 "Physis significa o vigor reinante, que brota, e o perdurar, regido e impregnado por ele. Nesse vigor, que no desabrochar se conserva, se acham incluídos tanto o 'vir-a-ser' como o 'ser', entendido esse último no sentido restrito de permanência estática. Physis é o surgir (Ent-stehen), o ex-trair-se a si mesmo do escondido e assim conservar-se" (HEIDEGGER, 1999, p. 45, grifo nosso). 
do ponto de vista identitário, a perspectiva dessubstancialista irá se referir não a um conjunto específico de comunidades, mas ao seu entorno ou a sua própria dissidência. Se fosse para figurativizá-la em um conjunto de homens, citaríamos a bela expressão de Bataille, "comunidade dos que não tem comunidade" (apud BLANCHOT, 1983, p. 9), uma comunidade de desertores e renegados, de homens destoantes, inconciliáveis, desmotivados a fazerem "obra da comunidade" (NANCY, 2000) ou a se reconhecerem enquanto comunitários ou comunitaristas; homens desobedientes à substância transcendental (tradições, mitos de origem, founding father). Ou ainda, "comunidade dos amantes" (BLANCHOT, 1983), de homens arrebatados pela paixão e pelo êxtase, condenados a viverem, a cada novo encontro, como nômades, entes sem destinação. Em uma palavra: Mitsein (pura abertura).

\section{Os contemporâneos}

Não é surpresa que este questionamento sobre o comum da comunidade tenha primeiramente surgido na Filosofia Política e na Literatura - domínios críticos e criativos -, num momento em que a representação, terreno do comum (Estado, espaços públicos, linguagem, etc.), entra em crise.

De fato, esses domínios do saber têm sido excepcionais em suas propostas de experimentação desse comum da comunidade, ou seja, o mergulho no munus, a busca não do ressarcimento do faltante (caro aos sociólogos do século XIX), mas do seu aprofundamento cada vez maior. Blanchot é, nesse sentido, um pensador exemplar: em um diálogo literário com Bataille, ele concebe a comunidade semelhantemente a Espósito e Nancy. Ao invés de uma instância de apaziguamento, homogeneidade e consenso, Blanchot defende a comunidade como um lugar do conflito, da heterogeneidade e do dissenso. Assim, ao invés de preencher a falta (originária) do ser, ela viria reforçá-la ainda mais.

O ser procura não ser reconhecido, mas contestado: ele vai, para existir, em direção ao outro, que o contesta e, às vezes, o nega, a fim de que ele exista somente nessa privação, que o torna consciente (é a origem da sua consciência) da impossibilidade de ser ele mesmo, de insistir como ipse ou, se o queremos, como indivíduo separado. (BLANCHOT, 1983, p. 17).

A comunidade é o lugar de origem de todo sujeito ou indivíduo, na medida em que esses emergem como confrontação identitária, pela exclusão daquilo que os constituem (as diferenças). Por outro lado, não deixa de ser paradoxal que o reconhecimento desses, enquanto sujeito ou indivíduo, é marcado pela impossibilidade de sê-lo. Por mais que eles se isolem, o outro os acompanha e os constituem ontologicamente, pois sem o outro não haveria consciência de si. Para Blanchot, a vinculação com o outro (comunicação), não é opcional (algo que acontece depois, por escolha do indivíduo); é a condição mesma do ser, de seu existir no mundo. 
Na verdade, a preocupação de Blanchot em toda sua reflexão sobre o ser comunal, é encontrar respostas contra a totalização - tanto na linguagem quanto na política (o comunismo) - presente em alguns ideais comunitários cujos sujeitos se encerram numa relação do "Même avec le Même", excluindo a diferença constituidora (BLANCHOT, 1983, p. 12). Ora, se essa diferença é excluída o que resta senão a morte da literatura e da própria da política? Ou seja, a morte da diversidade e das singularidades em favor de um coletivo homogêneo, tal como propôs o comunismo e as formações políticas totalitárias.

Esse questionamento, aliás, é retomado também por outro contemporâneo, Agamben, constituindo um dos pontos mais importantes de sua obra A comunidade que vem (1993). Para ele, a grande ameaça ao Estado totalitário é o qual-quer (quod-libet), manifestações singulares que não reivindicam nenhuma identidade, não representam nenhum grupo, nenhuma classe. Agamben observou de maneira ímpar essas formas políticas esvaziadas, não obstante, demasiadamente perigosas ao poder instituído. São resistências vindas, não como antes, de um partido político ou de um movimento social consolidado, mas de uma singularidade qualquer, como aquela que desafia o tanque de guerra na Praça da Paz Celestial. Tal singularidade não possui qualquer identificação ou território sobre os quais o biopoder poderia apanhá-la, agenciá-la, cooptá-la - um interlocutor com quem possa negociar. É exatamente isso que a faz perigosa.

O que mais impressiona nas manifestações do mês de Maio na China, é de fato, a relativa ausência de conteúdos determinados de reivindicação (democracia, liberdade são noções demasiado genéricas e difusas para constituírem o objeto real de um conflito, e a única exigência concreta, a reabilitação de Hu Yao-Bang, foi imediatamente concedida). Assim, tanto mais inexplicável é a violência da reação do Estado. É provável, todavia, que a desproporção seja apenas aparente e que os dirigentes chineses tenham agido, do seu ponto de vista, com mais lucidez do que os observadores ocidentais, exclusivamente preocupados em fornecerem argumentos à cada vez menos plausível oposição entre democracia e consumo (AGAMBEN, 1993, p. 66).

Na referida obra, Agamben (ibid.) elucida as singularidades (políticas e literárias) que reivindicam sua própria pertença como singularidade (impessoal, pré-subjetiva), ou seja, não como individualidade pertencente a uma instância universal, nem como universal a ser construído, reparado ou descoberto a partir de uma individualidade. Comunidade, desse modo, designa o conjunto das singularidades quaisquer que, do ponto de vista essencialista, nada tem em comum além do fato de serem singulares.

A expectativa por essa "comunidade que vem", um assalto generalizado ao poder por uma força múltipla, contínua e sem rosto (devir), é resultante da constatação do próprio autor de uma iminente crise da política moderna representacional, incapaz de conter um fluxo intenso em variação contínua. 
Porque o fato novo da política que vem é que ela não será já a luta pela conquista ou controle do Estado, mas luta entre Estado e não-Estado (a humanidade), disjunção irremediável entre as singularidades quaisquer e a organização estatal. (Ibid., p. 67).

Nessa crítica contra a totalização, presente em Blanchot (1983), Agamben (1993), mas, especialmente, em Espósito (2010) ${ }^{6}$, é possível visualizar a influência desconstrutivista (ou pós-estruturalista) em favor de um vitalismo da comunidade enquanto expressão do múltiplo. Embora o objetivo desses autores seja restabelecer a ontologia originária da comunidade (Mitsein) no horizonte do pensamento atual, isso não poderá ser atingido sem, antes, uma crítica às formas de apropriação do comum pelas formas de pensamento moderno, demasiadamente ontológicas e centradas no sujeito.

Cada filosofia política [moderna] assume, de fato, a forma de uma representação (do político). E a representação obedece, grosso modo, a duas exigências: aquela de impor uma certa forma ou uma configuração lógica à política; e aquela de reportar os muitos ao Uno, os conflitos à Ordem, a realidade à Ideia. (TARIZZO in PAIVA, 2007, p. 43).

O que esses contemporâneos da comunidade tentam explicitar é o fato de que a tradição política moderna nada mais fez do que essencializar o "supostamente" ${ }^{\text {"7 }}$ comum expropriado. Ora, é justamente esse desejo de reparação que legitimou, ao longo da história, a apropriação de territórios, línguas, tradições num Uno, numa Ordem, numa Ideia. Por outro lado, e seguindo a trilha desses filósofos contemporâneos da comunidade, Ser/Estar em comunidade não é a busca pelo ressarcimento, mas o aprofundamento ainda maior da falta.

Isso significa compreender a comunidade como externalidade em relação ao indivíduo. Não como projeção de interesses individuais num espaço (por exemplo, a internet), tão comum às teorias sobre redes sociais e agrupamentos urbanos. Estas não passam de uma grande interioridade só que lançadas num lugar externo. Diferentemente de uma projeção interesseira ou de um conjunto de individualidades, são estas concepções comunitárias (de Espósito, Nancy, Bataille e Agamben), onde o indivíduo se vê extraviado; ele vê se esvair sua subjetividade e interioridade por um traço que o arranca de si (cum, mit), obrigando-o a encarar o seu fora.

É como a "experiência interior" de Bataille, entendida não como consciência de si (diálogo de mim comigo mesmo), mas sentimento de si a partir de numa descontinuidade aberta pelo transbordamento da vida. Essa experiência, segundo ele, comparece ao ser

6 Para Espósito (2010), o projeto político moderno do ocidente consolida-se por um "paradigma imunitário", a conservação da vida através de sua "in-munização" (neutralização do munus). A imunização constitui um importante dispositivo biopolítico que atua tanto no evitamento de um íntimo contato humano quanto na diminuição da frequência de uma relação horizontalizada entre os governados. Essas formas de relação constituem, na verdade, modos de contágio que poderia induzir a uma "expansão da vida", pondo em risco um governo biopolítico.

7 Diz-se aqui "supostamente" porque, como defende Anderson (2008), esse comum é sempre imaginado, construído social ou discursivamente, sobre um fundo comum (vazio) originário. 
"na crise que o põe à prova, é a atuação do ser numa passagem que vai da continuidade à descontinuidade, ou da descontinuidade à continuidade" (BATAILLE, 1992, p. 95).

A ausência de substância, de propriedade ou domínio de si (próprio), segundo a concepção comunitária desses pensadores contemporâneos da comunidade, expõe não apenas as condições de uma política futura (como vimos em Agamben), mas também o que há de verdadeiramente comum na comunidade (o munus).

Se Nietzsche (outro contemporâneo) falava de uma febre histórica que devorava sua geração, é visível a febre de substância (como exigência da verdade) que marca o nosso tempo. De fato, o sucesso de um conceito pleno de substância como a Gemeinschaft de Tönnies - em conformidade com o quadro teórico de correligionários como Comte, Le Play e Marx - só pode ser compreendido numa época de glória tanto do materialismo histórico quanto das representações, amparados nos quais se motivava toda a luta pelo comum.

E de fato se lutou. O século XX é repleto de conflitos em nome da comunidade (na Europa, o nazifacismo; na América, o comunismo; no oriente médio, os fundamentalistas religiosos). Não à toa que muitas das atuais formulações sobre a comunidade são acompanhadas de um cuidado ético e, curiosamente, como questão comunicacional ${ }^{8}$. Por quê? Porque somente a ética é capaz de interditar a completude do ser ou a sua realização no coletivo; porque institui o outro (diferente) como fundamento do ser, como pressuposto do si - tal como observou Blanchot (na esteira de Lèvinas). Mas, sobretudo, porque põe em questão o vínculo como elemento originário do indivíduo e do ser propriamente dito. O vínculo, tal como pensou Sodré, enquanto "radicalidade da diferenciação e aproximação entre os seres humanos"; não obstante, "o núcleo teórico da comunicação" (SODRÉ, 2002, p. 223).

\section{A aventura do pensamento no interior da fratura}

A crise do conceito de comunidade tem se expressado de muitas maneiras, desde as indagações sobre os perigos de se legitimar as formas de associação humana num cenário de extremo utilitarismo, até o questionamento sobre a qualidade dos vínculos sociais na atualidade. No campo comunicacional, no entanto, essa crise parece ainda mais urgente, como se percebe no conjunto de questões cada vez mais usuais: comunidades virtuais são verdadeiramente comunidades? Os moradores das favelas compartilham um munus? A comunicação comunitária deveria tratar do fenômeno da vinculação humana ou do uso de aparelhos contra-hegemônicos? A busca pelo fundamento torna-se, pois, incontornável.

O que é, então, comunidade?

Antes de responder tal pergunta é importante destacar que não se trata de um falso problema ou pura especulação abstrata. Ao contrário, da fratura aberta por esse questionamento podemos recuperar a singularidade obscurecida pela substância comum. A urgência de uma reinterpretação da comunidade, portanto, longe de um simples exercício de refinamento filosófico, marca a irrupção de um campo de discursividade.

8 Cf. Communitas, ethiké In SODRÉ, 2002, p. 169-220 
A resposta que propomos dar à questão da comunidade, obviamente seguindo a trilha desses contemporâneos, é: comunidade é um acontecimento, um sentido que percorre e transpassa os indivíduos, neles despertando a sua condição originária de ser-com (Mitsein), ser-uns-com-os-outros, homens originariamente devedores uns com os outros.

Não se trata, todavia, de um acontecimento no sentido trivial, como equivalente a um evento, senão esperado, pelo menos sem poder de rompimento - algo como: o natal é um acontecimento importante do mês de dezembro. Aqui, a ideia de um sentidoacontecimento tem um significado mais radical, associando-se ao desligamento com as estruturas de sentido vigente, tal como enfatizado por Deleuze (2007) em sua Lógica do sentido, onde o autor retoma a moral nietzscheana (mas também estoica) do amor fati: "devemos querer o acontecimento".

É pertinente aqui a história de Joe Bousquet, poeta francês que, ferido durante a Primeira Guerra Mundial, fica preso a uma cadeira de rodas. A bala que perfura a espinha de Bousquet não aniquila sua vida orgânica, mas a inorgânica, de seus sonhos de glória, o esplendor de um retorno heróico. Uma morte em vida. A ferida produzida pelo projétil é um acontecimento que o poeta não deverá ressentir, mas ser digno dela, reinventando-se a si, ou seja, sua vida inorgânica. É isso o que significa querer o acontecimento:

[...] tornar-se digno daquilo que nos ocorre, por conseguinte, querer e capturar o acontecimento, tornar-se o filho de seus próprios acontecimentos e por ai renascer, refazer para si mesmo um nascimento, romper com seu nascimento de carne. Filho de seus acontecimentos e não mais de suas obras, pois a própria obra não é produzida senão pelo filho do acontecimento. (DELEUZE, 2007, p. 152).

E o que isso tem a ver com a comunidade? Ora, a comunidade é como a bala que perfura a carapassa do indivíduo (a experiência de um sentido-acontecimento) que o esvazia, que o descentra, obringando-o à vinculação. Tal esvaziamento conduz o indivíduo ao lugar de sua procedência, à sua condição originária de ser-com (Mitdasein). É somente a partir de tal experiência que ele abandonará a sua vida egoica (autocentrada e autossuficiente), partindo para um sem número de relações que constitui a própria vitalidade do homem, uma vida de contágio, de proliferação das singularidades vitais:

[...] o homem vem ao mundo recortando sua própria identidade na continuidade do não ser que surge. Em outras palavras, sua vida coincide com os limites que o separam dos outros, fazendo dele esse ser específico que é. Portanto, ele está obrigado a defender esses limites para assegurar sua sobrevivência. Inclusive, porque identifica esses limites com a circunstância de ser em vez de não ser, o aterroriza a possibilidade de perdê-los. Este instinto de conservação, no entanto, não esgota sua experiência: pelo contrário, constitui seu vetor menos intenso, enquanto apenas biológico, ao qual se entrelaça uma pulsão absolutamente oposta que, sem anular a primeira, o opõe surdamente. Deste modo se dá a paradoxal situação de que o indivíduo deseja o que teme - justamente perder os limites que o "fazem" ser - movido por uma invencível nostalgia por seu estado precedente, e sucessivo, de não-ser individual. Daí uma situação de perene 
contradição entre desejo e vida. A vida, em última análise, não é senão o desejo (de comunidade), mas o desejo (de comunidade) se configura necessariamente como negação da vida. (ESPÓSITO, 2007, p. 196, grifo nosso).

Com essa definição de comunidade, acreditamos estar aptos a responder questões prementes tais como: o que faz com que algo seja experimentado como comunidade e não como simples agrupamento humano (autoafirmativo)?

A "diferença ontológica", nesse caso, pode ser observada como fenômeno comunitário, o que abre a possibilidade de novos objetos comunicacionais (experiência comunitária ou dessubjetivação, vinculação com estranhos, extermínio ou manifestação da singularidade), além de um modo sensível de mensuração. Já não serve as tradicionais ferramentas das ciências sociais, excelentes (diga-se de passagem) para explicar e compreender a comunidade em sua ontologia estável, mas que sucumbem diante da vertigem do abismo em que a colocamos.

\section{Experiência comunitária}

Ser/estar na comunidade, portanto, constitui uma experiência. Não qualquer experiência, mas aquela sentida como subtração, perda, dilaceração do si. A experiência da comunidade, segundo Espósito, constitui uma experiência sem sujeito, o toque da morte subjetiva (Blanchot; Bataille), como algo exterior que nos carrega sem que possamos fazer qualquer coisa além de sentir: frente à comunidade somos vítimas, meros objetos.

Se para alguns ser arrastado para fora de si (como sugere a experiência comunitária) soa como algo negativo (sobretudo para aqueles que desejam preservar-se como indivíduo in-munizado); para outros pode significar a oportunidade única de uma vida repleta de vitalidade. Pois, extraviar-se ou perder o controle de si, abre-se como possibilidade de irrupção do novo, de uma nova vida inorgânica, de um encontro inesperado.

Esse encontro pode acontecer no próprio indivíduo (desde que como "experiência interior" batailleana, transformação, e não como reforço ou reiteração de si), como fora dele, nos mais diferentes espaços sociais, nas mais improváveis situações coletivas.

Vattimo, citando a interpretação de Gadamer sobre o parágrafo 9 da Crítica do Juízo de Kant, argumenta a beleza do "ser-com" ou do "estar-junto" em situações frívolas como numa conversa informal ou ainda na recepção de objetos artísticos.

[Nós poderíamos] identificar a experiência do belo com uma experiência vivida de comunidade, que não é nem idêntica ao prazer de uma descoberta científica ou de uma afinidade moral, mas é um sentir-se "bem" com o nosso próximo na contemplação, ou ainda na apreciação de certos objetos, não enquanto úteis, ou enquanto bons, ou enquanto verdadeiros, e sim justamente enquanto belos. (VATTIMO in PAIVA, 2007, p. 64).

A experiência estética da comunidade de que fala Vattimo pode ser entendida como experiência da subtração (des-in-munizar), encontro inesperado na multidão e 
na contemplação (tal como a literatura, como frisou Blanchot). Vale dizer que essa experiência foi obliterada na modernidade em seu processo de inmunização, que trancafiou a arte "social" da antiguidade (templos e teatros) no domínio privado (a exemplo dos retratistas), desvinculada de qualquer laço ou dívida (do artista para com a sociedade, da sociedade para com o artista), restrita apenas a uma relação de equivalência: compra e venda.

Convém perceber que essa ideia de privatização constitui, ainda hoje, a condição fundamental da apreciação estética (por exemplo, em Theodor Adorno). Todavia, frente às experiências (recepção) solipsistas da obra de arte, surgem centros agregadores da diferença, os quais colocam em questão a beleza do estar-junto, a exemplo dos espetáculos musicais, salas de cinema (num período de declínio da solipsista televisão), lugares onde não podemos mais ficar alheios.

Eduardo Yuji YAMAMOTO é jornalista e mestre em Comunicação pela Universidade Estadual Paulista (UNESP); é doutorando em Comunicação e Cultura pela Universidade Federal do Rio de Janeiro (UFRJ).

yujieduardo@gmail.com

\section{Referências}

AGAMBEN, Giorgio. A comunidade que vem. Lisboa: Presença, 1993.

O que é o contemporâneo? e outros ensaios. Chapecó: Argos Editora, 2009.

ANDERSON, Benedict. Comunidades imaginadas. São Paulo: Cia das Letras, 2008.

BATAILLE, George. A experiência interior. São Paulo: Ática, 1992.

BLANCHOT, Maurice. La communauté inavouable. Paris: Minuit, 1983.

DELEUZE, Gilles. Lógica do sentido. São Paulo: Perspectiva, 2007.

ESPÓSITO, Roberto. Communitas. Buenos Aires: Amorrortu, 2007.

Bios. Biopolítica e filosofia. Lisboa: Edições 70, 2010.

HEIDEGGER, Martin. Introdução à Metafísica. Rio de Janeiro: Tempo Brasileiro, 1999.

NANCY, Jean-Luc. La comunidad inoperante. Santiago de Chile: Arcis, 2000.

PAIVA, Raquel (org). O retorno da comunidade. Rio de Janeiro: Mauad X, 2007.

SODRÉ, Muniz. Antropológica do espelho. Petrópolis: Vozes, 2002.

Artigo recebido em março e aprovado em junho de 2013. 